\section{The inappropriate question syndrome}

DeAr SirS

We describe a syndrome whose features will be recognised easily by most psychiatrists attending College meetings. It is of importance because of the amount of time that this syndrome wastes, and the annoyance it causes.

\section{History}

Although no explicit descriptions of this syndrome exist, it is probable that inappropriate questions have existed for many years. The term langweiligedummfrage is said to be in use by the German school of psychiatry (sometimes attributed to Kraepelin), while the French refer to Bouffee Questionante. The syndrome escaped inclusion in DSM-III-R, but it is likely that the Post-Presentation Extended Interrogative Disorder will be defined in DSM-IV (provided its vociferous exponents allow sufficient time for its discussion).

\section{Clinical description}

The setting of this syndrome is most commonly College meetings after the presentation of a paper. The question bears little or no relevance to the presentation just made, and usually takes the form of an address, lasting several minutes. The content of the question is variable, usually referring to a questioner's previous work, often mentioning eminent people or places of distinction. Operational criteria are proposed by the authors (see Table I).

This type of question causes a blank look to appear on the face of the presenter of the paper, and the audience to become restless. Frequently the question expands to fill the whole time available for questions for that presentation.

Unusually in psychiatry, the syndrome seems to strike more males than females, and there is a suggestion that its prevalence increases with age (and is rare below consultant grade). There does seem to be an association with narcissistic, histrionic and antisocial personality types. From a psychodynamic perspective, the ego is engaged before the intellect. Transcultural aspects may be important, with the threshold for inappropriateness set at a different level in North American and other ethnic groups.

\section{Management}

Management is a difficult topic. The questioner may respond to counselling in mild cases, and this can be reinforced by video feedback. Assertiveness training should be offered to people chairing College meetings. Prophylactic measures may be required, with the Chair overtly ignoring people with the syndrome. In extreme cases, amputation from the College mailing list may be required.

\section{Discussion}

We have presented a common and distressing syndrome which afflicts a few but which causes suffering to many others. Validation of the definition of the syndrome is required before prevalence studies and treatment trials are undertaken. Methods of primary prevention, such as education, should be considered. In the era of the White Paper, the use of our diagnostic criteria may facilitate audit of question time at College meetings.

P. MADEley

D. B. MUMFORD

University of Leeds

C. A. Biggins

Department of Psychiatry

Leeds LS2 9LT

TABLE I

Diagnostic criteria for Inappropriate Question Syndrome

(a) Little relevance to the presentation;

OR

Question takes the form of a statement (pseudoquestion).

(b) Question takes one minute or longer to articulate

(c) At least one statement similar in content to the following:

"I have two/three/nine brief points to make ..."

"I wonder if the speaker could comment on a study I did..."

"When I was working with Prof ..."

"I recently reviewed the literature on..."

"I did a study ten years ago which..."

\section{The College Hierarchy Agenda Organisation Scale (CHAOS)}

\section{DeAR SIRS}

This scale is to be used by College staff when receiving agenda items for all College Committees and Working Groups. Agenda items are only to be placed on a Committee Agenda if they score over 20 on this scale. The higher the total score, the further up the Agenda the item should appear. No items with a total score less than 30 should arise before lunch.

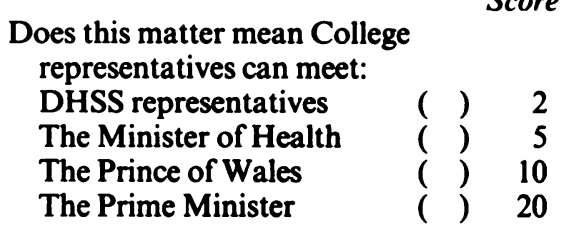

(2) Does this matter mean College representatives can visit:

$\begin{array}{llr}\text { USA } & \text { ( ) } & 5 \\ \text { The Greek Islands } & (\text { ) } & 5 \\ \text { Chad } & (\text { ) } & -5 \\ \text { Scotland } & (\text { ) } & -10\end{array}$


(3) Will this issue:

Allow the Chairman to speak for ten minutes without interruption

Allow a Committee Member to reply for ten minutes without interruption

Lead to extensive discussion

Engender universal agreement

(4) Can this matter be:

Subsumed to another agenda item

Referred to another committee

Spoken to by an elective mute

Seized on by the Press

(5) Does this matter concern:

The public's alcohol consumption

Doctors' alcohol consumption

Psychiatrists' alcohol consumption

College profits from brewery shares

(6) ( ) -10

( ) 5

( ) 10

All Committee Members ( ) -5

The College Membership （ ） -10

(7) This issue might give rise to:

A Special Interest

Group

A new Section

The resignation of a

member of College staff $(\quad)-30$

An organisation without

College responsibility

for funding

( ) 20
(8) Does this matter offend:

Psychologists

Social workers

The Prince of Wales

College staff

() 10

() 5

( ) -5

() -10

TOTAL SCORE:

*(This document has been reprinted without the authority of any College Committee or Section!)

Allium PORrum

\section{Psychiatry in bookshops}

DeAR Sirs

There is current debate about the position of psychiatry in the 1990s. Within the profession there seems to be a consensus that psychiatry is a medical subspeciality. But what do the general public think?

A well-known Bristol academic bookshop may have the answer. Their psychiatry section is not to be found between pathology and radiology but appears separately, next to Alternative medicine.

Presumably customers find this arrangement more suitable.

I wonder what the situation is like nationally?

Royal United Hospital, Bath

DARRYL WATTS

\section{On-call system for child psychiatry}

DeAr Sirs

Since writing the article on the state of liaison in psychiatry (Psychiatric Bulletin, June 1990, 14, 322) it has been brought to my attention that an extensive on-call system exists for child psychiatry in Bloomsbury.

Department of Maxillofacial Surgery

\& Oral Medicine

Eastman Dental Hospital,
Charlotte Feinmann 